\title{
Uncertainty of, and stakeholder response to, emerging technologies: food nanotechnology in Japan
}

\author{
Masashi Tachikawa* \\ College of Agriculture, Ibaraki University, Ami-town, Ibaraki, 300-0393, Japan
}

\begin{abstract}
Food nanotechnologies pose a number of difficulties in risk assessment and risk management, such as data collection, definition, and classification of materials. There is no clear consensus as to what is to be regulated and who would be involved in the area of food nanotech. In this paper, I have described how stakeholders respond to various uncertainties related to food nanotechnologies, and tried to elucidate the dynamic nature of uncertainties and societal stakes that occurred during negotiations among various stakeholders in the case of food nanotechnologies in Japan. Three ways taken by stakeholders to respond to these situations were analyzed based on the experiences of participatory research. These are: (1) trying to reconstruct uncertainty while the stakes are regarded as given, (2) trying to reconstruct stakes while the uncertainty is regarded as given, and (3) trying to reconstruct uncertainty and stake at the same time. I conclude with a discussion of some ethical implications for stakeholder identification and dealing with uncertainty.
\end{abstract}

KEY WORDS: Food nanotechnology $\cdot$ Uncertainty $\cdot$ Stakeholders $\cdot$ Japan

\section{INTRODUCTION}

Since the turn of the century, nanotechnology has been one of the most important areas of innovation, and the frontier of application is expanding from computers to life sciences. Researchers are busily seeking novel applications for this new technology, and food is no exception (USDA 2003). As the technology employed in this area is so broad, it is more common to use the word 'nanotechnologies' rather than 'nanotechnology.' In this paper, food nanotechnologies (food nanotech) is defined as a group of technologies applied to food-related products that use nanotechnology.

As there is no agreed definition, it is very difficult to enumerate the food nanotech products on the market. Some product inventories have been created provisionally in the United States ${ }^{\underline{1}}$ and Japan ${ }^{\underline{2}}$, and a number of nano-claimed food items are being sold on the market. The most frequent application of food nanotech is in health food, such as dietary supplements. Some of the products manufactured in Japan are exported overseas. Examples of applications of nanotech to food in Japan include cooking oil with added iron, health foods with mushroom extract, and health food containing nano-sized pieces of platinum. The Japanese government forecasts that the food nanotech market, including food, packaging and kitchenware, will reach 250 billion yen in 2030, which would well surpass the size of the cosmetics market (METI 2005).

\footnotetext{
${ }^{1}$ W. Wilson Center for International Scholars, Project on Emerging Nanotechnologies (PEN). www.nanotechproject. org/inventories/

${ }^{2}$ National Institute of Advanced Industrial Science and Technology (AIST), A Nanotechnology-claimed Consumer Products Inventory in Japan. www.aist-riss.jp/db/nano/
} 
While there are some nano-claimed food items in the Japanese marketplace, there have been no salient discussions on regulatory issues regarding food nanotech in Japan. This situation contrasts with other industrial countries such as Australia, Canada, New Zealand, the European Union, and the United States (Pelley \& Saner 2009, Gergely et al. 2010). Currently, regulatory bodies such as the Ministry of Health, Labour, and Welfare (MHLW), and the Ministry of Agriculture, Forestry, and Fisheries (MAFF) are in the stage of internal information gathering on the health and environmental implications and policy trends in other countries, mainly in European Union countries and the United States.

While there is no well-established evidence of risk regarding food nanotech, some civil society organizations have been critical of possible hazards and the lack of preparedness of the regulatory system regarding nanomaterials in food-related products. For example, ETC Group (2004) and Friends of the Earth (2008) have voiced concerns over the health and environmental risks of food nanotech, and have called for precautionary action including a moratorium on food nanotech until regulations are established.

However, food nanotech poses a number of difficulties in risk assessment and risk management, such as data collection, definition, and classification of materials. For example, regulatory bodies in Japan have not initiated discussions on regulatory definitions and scoping issues in a domestic context regarding food nanotech. Therefore, there is no clear consensus as to what is to be regulated and who would be involved in the area of food nanotech. The current situation is closely related to uncertainties surrounding other emerging technologies (Yamagichi \& Hibino 2009).

Generally speaking, emerging technologies (Yamagichi \& Hibino 2009) give rise to various uncertainties in scientific and regulatory terms, and because of this, greater societal stakes are often discussed in terms of their applications. Stakes here mean interests or concerns shared among society when emerging technologies are to be introduced.

Employing the term 'post-normal science,' Funtowicz \& Ravetz (1993) have referred to a form of science that has a high level of 'uncertainty' and 'stake' in society. This constitutes the rationale as to why society needs to get involved in discussing the way in which the science is to be introduced into society. In this sense, food nanotech and nanotechnology in general can be considered as post-normal sciences. Here I would like to emphasize that the relationships between uncertainty and societal stake need to be examined carefully, as they are not always independent or self-evident. A change in this uncertainty would greatly affect the nature of the stake in society and the types of stakeholders involved. It is worthwhile pursuing the dynamism of these relationships.

In this paper, I describe how stakeholders respond to this uncertainty, and try to elucidate the dynamic nature of uncertainty and societal stakes that occurred during negotiations among various stakeholders in the case of food nanotech in Japan. The paper is organized as follows. In the first section, I describe the nature of uncertainty that entails food nanotech, which can be classified into 2 kinds; scientific and regulatory. Then I describe how various stakeholders respond to the above-mentioned uncertainties based on information that I have collected through interviews and participatory research events organized in Japan. In the third section, I summarize the various observations made and draw some implications using 3 types of interaction between uncertainty and stake. Sometimes stake and uncertainty are not self-evident, and can be reconstructed through negotiations among stakeholders. Finally, I conclude with a discussion of some ethical implications for stakeholder identification and dealing with uncertainty.

\section{UNCERTAINTIES}

\section{Scientific uncertainty}

Like other emerging technologies, such as biotechnology, nanotechnology entails scientific uncertainties that need to be explored through investigation. Two of the most contentious issues are the risks to human health and the environment. Materials exhibit different properties at the nanoscale, such as reactivity, color, strength, and electronic transmissibility. The bottom line is that these novel characteristics of a material at the nanoscale are difficult to anticipate beforehand, based on existing knowledge of the materials at bulk level. For example, a gold nanoparticle does not show a golden color, but an orange or even red color at nanometer scales. A novel property might create a new area of application for the material, but, at the same time, could pose a novel risk to human health and the environment. This kind of scientific uncertainty is equally applicable to food nanotech. In the case of food nanotech, the novelty is more related to taste, color, digestibility, solubility, and so on. Scientific uncertainty is now being 
discussed in the field of food safety: for example, how the novel characteristics of nanoparticles in food could have a serious adverse effect on the absorption, distribution, metabolism and excretion (ADME) of the material. A guidance document released by the European Food Safety Authority (EFSA 2011, p. 9) on the risk assessment of nanomaterials states:

The absorption, distribution, metabolism and excretion (ADME) parameters are likely to be influenced by both the chemical composition of the ENM (engineered nanomaterials) as well as its physicochemical properties (e.g. size, shape, solubility, surface charge and surface reactivity).

The possible risk posed by nanomaterial depends not only on size, but also on the effects of surface structure, coating, $\mathrm{pH}$ and other factors. Other features of nanomaterials, such as soluble/insoluble and organic/inorganic, are also thought to be important factors in differentiating nanomaterials in terms of risk. It is important to explore the various dimensions of risk-related factors that are still under development. The unintended absorption of undesirable material into the human body along with nanomaterials is also regarded as a possible risk of food nanotech. This hypothetical movement of nanomaterial is called the 'Trojan horse effect' (EFSA 2011).

Uncertainty is not easily reduced because we still do not have standard testing protocols for food safety, widely agreed measurement systems, or a classification system for materials (nomenclature). This is a kind of dilemma in which it is hard to establish a standard without a rich repository of tested data on the one hand, but it is equally hard to collect reliable data without a standardization of testing methods on the other.

\section{Regulatory uncertainty}

Throughout the process of risk analysis, such as the accumulation of risk-assessment data, and introducing control measures to reduce risk, it is imperative to identify what kinds of risks need to be regulated. In order to implement appropriate procedures related to risk analysis, it is crucial for risk managers to identify hazards and risks for regulatory purposes and to establish definitions of regulated articles. However, in the area of food nanotech, there is no well-agreed definition of food nanotech or nanomaterial at either the domestic or the international level. As will be discussed below, European regulatory bodies have made efforts to introduce a definition of nanomaterial in novel foods, but their efforts have not yet reached a conclusion. This lack of a definition for regulatory purpose is delaying the systematic accumulation of tested data, and the establishment of official protocols for safety tests ${ }^{3}$.

For regulatory purposes, the classification and scoping of nanomaterial are very contentious issues in developing a regulatory framework. More research is needed to collect reliable data. An idea of the classification of food nanotech was proposed in a report on the research organized by the Japanese Food Safety Commission (FSC) (Toray Research Center 2010). The classification was made using the following criteria: naturally occurring/manufactured, organic/inorganic, change in absorption, eating experiences, and other such factors. In 2011, the EFSA proposed a decision tree to indicate the classes of materials that are required to be evaluated by a risk assessment. These classification efforts are all based upon the intention to avoid imposing an unnecessary regulatory burden on food that has a history of safe use, while at the same time delineating the possible risks posed by nanomaterials in food. For example, micelle in milk and cyclodextrin (CD), which have a long history of safe use, fall into the category of nano-size material as far as size is concerned. Therefore, classification and scoping are very important as size alone is not a sufficiently good indicator to delineate what should be regulated.

Put shortly, regulatory bodies have not decided yet what should be regulated or upon a definition of food nanotech. Therefore, regulatory uncertainty exists and it is hard to envision what kind of regulatory actions should be taken when food nanotech products are placed on the market. This regulatory uncertainty in terms of scope and definition of food nanotech poses difficult issues to commercial entities that are developing products in the sector. If regulatory bodies were to introduce stringent regulations such as pre-market authorization requirements and mandatory labeling, it would be more costly to develop food nanotech products for the market. On the other hand, if the government were to simply urge industry to consult with regulatory bodies regarding their products, such as was the case with

\footnotetext{
${ }^{3}$ In this respect, the concept of co-production (Jasanoff 2004) gives us a key to understanding the relationship between 2 uncertainties. I would argue that these 2 uncertainties need to be settled simultaneously, and this situation is exactly the same as that Jasanoff (2004) referred to in her coproduction argument. That is, natural and social orders are inseparable and produced together.
} 
biotech crops in the United States, the food nanotech industry would face a totally different situation.

While regulatory uncertainty is observed internationally, European nations seem to be taking a more precautionary approach to food nanotech. Before settling issues related to risk or definition, the EU has adopted revisions to some regulations that take nanotech into consideration. For example, in 2008, the EU Regulation of Food Additives (no. 1333/2008 of the European Parliament and of the Council of 16 December 2008 in food additives) included an article that stipulates mandatory labeling of nanomaterial, with an ambiguity of what nanomaterial is. Here, 'regulatory uncertainty' means how this article would be applied in the real world, and what the socioeconomic impact would be on the market. Compared with the European situation, the United States seems to be more cautious about introducing this kind of regulatory hurdle until enough scientific information has been collected to justify risk-management measures (Food and Drug Administration [FDA] 2007). Americans also seem to prefer the consultation method for the sharing of scientific information between industry and regulatory bodies. In order to facilitate this kind of consultation, an FDA task force has recommended the issuance of guidance documents to industry (FDA 2007).

\section{STAKEHOLDER REPONSES TO UNCERTAINTY}

In this section, I describe how various stakeholders are responding to the above-mentioned uncertainties. The issue here is how each individual stakeholder sees these uncertainties, and whether or not they exhibit a reaction against them. From now on, I would like to draw information mainly from Japanese experiences, such as interviews and participatory research events ${ }^{4}$ organized by my colleagues and myself. In order to characterize the Japanese situation more clearly, I will refer to the EU and US situations as appropriate.

As for stakeholders, there are many types involved in food nanotech. However, I would like to look at 3

\footnotetext{
${ }^{4}$ These events are (1) consensus conference co-organized by my colleagues and the science communication unit (CoSTEP) at Hokkaido University in 2008 ; (2) an expert panel organized by a group of researchers mainly from the University of Tokyo in 2010; and (3) a focus group interview with consumer advisers in 2010. Details of the events can be found in the literature, such as Mikami et al. (2009) and Yamaguchi (2010).
}

kinds of stakeholders in the following sections to simplify the situation, namely: the government (regulator), industry, and consumers. Referring to these 3 stakeholders does not mean there are no variations in reaction among individual stakeholders. In fact, the reality is quite the opposite, and it is sometimes very difficult to generalize the responses of individual stakeholders. This is quite true for industry, and this variability will be referred to later in detail.

\section{Government}

The government, or the regulator, holds various stakes when emerging technologies are introduced into society. Basically, a regulator has to strike a balance between benefit - such as economic prosperity through innovations - and risk - such as adverse effects on human health and the environment. Emerging technologies often entail uncertainties and, therefore, the government is expected to deal with these uncertainties through policy measures, such as research into safety and risk management. Also the existence of uncertainty leaves room for government bodies to determine how they will be involved in regulations in the future. The role of the government also differs depending on the nature of how an emerging technology is to be applied. In other words, different ministries would be involved depending on the area of application. Therefore, the government's role as a stakeholder would also differ. If food nanotech were used only in micelle-processing techniques, no concerns over safety would be raised by the government, and no further intervention from the government would be expected.

Before describing the attitude of the Japanese government toward food nanotech and its related uncertainty, I would like to refer to the EU and the US situations. This is because the EU and the US have already officially started regulatory discussions, and we can observe how each government has been trying to deal with the issue of uncertainty with respect to food nanotech.

As for food nanotech, European nations have already implemented initiatives to secure the safety of food nanotech-related products. For example, the EU Food Additive Regulation (No. 1333/2008) has been revised to include labeling requirements for materials at the nano scale. In addition, the Novel Foods Regulation (No. 258/97) has been regarded as a major policy tool to address the issues of food nanotech. In the draft version of the regulation, premarket authorization and mandatory labeling on 
nanomaterials in food were proposed along with a definition of nanomaterial. In the regulation, European nations seek to introduce precautionary measures for food nanotech by applying an authorization procedure and proposing not to commercialize products until appropriate risk-assessment measures are put in place. This precautionary stance is related to the current scientific uncertainty surrounding food nanotech. At the end of March 2011, a revision to the regulation failed due to other major contentious issues of novel food, notably cloned animals.

The United States is taking a rather cautious position about introducing a new regulatory system. Based on a series of public meetings and discussions by an internal task force, the FDA recently issued a draft guidance document (FDA 2011) in which it expresses its intention to ask companies about the properties of FDA-regulated products that contain nanomaterials or involve nanotechnology. By issuing guidance, the FDA is urging companies to consult it at early stage of commercial development when the companies are using nanotechnology in their products. However, the FDA recognizes no need to introduce new regulations to manage uncertainty over nanotech products. This position contrasts that of the Europeans.

Compared with EU and US governments, the Japanese government has not officially initiated any measures with regard to uncertainty over food nanotech. This regulatory inaction by the Japanese government shows a sharp contrast with that of EU and US governments, taking into account the situation in Japan regarding the nanotech food market $\underline{\underline{5}}$. This inaction is partly explained by the fact that no major health issues have been reported to date and the limited human resources within administrative divisions. In an interview, a government official expressed a wish to collect information first and monitor regulatory trends among other governments, in particular those of the EU and US. The official was of the opinion that it would not be too late for the Japanese government to introduce regulations even after

\footnotetext{
$\underline{5}$ The Japanese government's belated action toward emerging science and technology can also be noted in biotechnology. Mandatory safety testing of the environment for transgenic crops was only established after the enactment of the Japanese Cartagena Law in 2003, and this was very late compared with the situation in the US (1986 by the Coordinated Framework) and the EU (1990 by the Environmental Release Directive). The Japanese government tends to be very cautious in introducing regulations that have not been widely adopted in the international arena.
}

the EU or US had started to regulate the area. Currently, regulatory bodies, such as MAFF, have introduced risk-based policies and have set management priorities, with periodical updates, of food-borne risks by listing chemical substances and microorganisms. It is not expected that nanomaterial will be included on the list as MAFF is sticking to the current criteria for inclusion ${ }^{6}$. In addition, MHLW, which has shared responsibility for food safety with MAFF, has not officially started any regulatory discussion regarding food nanotech.

While no major regulatory action has been taken in Japan, the FSC - a risk assessment agency under the Prime Minister's Cabinet Office-has started collecting information. The FSC dispatches experts to Codex and the EFSA to discuss food nanotech and gather information from foreign governments related to risk assessments of food nanotech. The FSC also commissioned a study to collect scientific articles related to food nanotech and conduct a mail survey of Japanese food-related companies to collect information on R\&D activities by industries related to food nanotech.

\section{Industry}

Private industry is now facing both types of uncertainty, scientific uncertainty and regulatory uncertainty, and is thus facing a complex situation. We can see various responses made by the food industry in this situation. Below are some typical measures industry is taking to tackle these uncertainties.

(1) Scientific inquiry and product development: While it is impossible to enumerate all the food companies involved in food nanotech, some companies in Japan have already started to commercialize products that claim to be using nanotechnology. Some of the companies I interviewed have conducted extensive safety and effectiveness tests, including clinical trials. It is regarded as a company's responsibility to secure the safety of its products, and these companies are making efforts to publicize the findings of these safety tests. This is one way to respond to scien-

\footnotetext{
${ }^{6}$ As for hazardous microorganisms, the following 4 criteria are considered for inclusion on the priority list for risk management: (1) hazard characterization, (2) number of infected persons, (3) interest of stakeholders, (4) international trends - in particular the setting of a standard by Codex. Here we can see the outward looking attitude of the Japanese government, which is a major factor when considering regulatory action.
} 
tific uncertainty, but some companies might not make the same sort of effort. As neither government nor any industry association has stipulated a safety standard for food nanotech products, it is left to each company's discretion as to how much it considers additional safety testing desirable for its products before placing them on the market.

(2) Measures to counter regulatory uncertainty: Regulatory uncertainty poses another challenge to companies that manufacture food nanotech products. As mentioned above, a regulatory definition of food nanotech has not yet been agreed upon, and it is difficult to foresee what kind of regulatory measures will be introduced. Against this backdrop, companies could take measures to avoid this kind of uncertainty. One option would be to introduce their own guidelines, or a voluntary code of conduct. In the area of industrial nanomaterial, there are efforts being made to introduce voluntary guidelines to secure safety and accountability for customers. One notable case is the Nano Risk Framework established by Dupont and the Environmental Defense Fund in the United States.

However, there is no such effort being made to date in Japan. This is partly related to the industry's posture towards the government, which has been fostered by history. Since World War II, the Japanese government has played a leading role in and has contributed to economic growth. Given this situation, the Japanese industry tends to be responsive to government initiatives and shows a rather passive attitude when a new regulatory framework is introduced (Murakami 1984). This situation somehow seems to remain even today. Compared with its EU and US counterparts $^{\underline{7}}$, the Japanese industry has not made any attempts to introduce voluntary codes related to nanotech. Basically, industry is rather passive and is content to wait for a government decision on regulatory action related to nanotech. This kind of attitude on the part of industry can also be observed in the results of a survey of companies commissioned by the FSC (Toray Research Center 2010). Many of the firms surveyed mentioned the importance of risk issues and also expressed a wish for the government to take the initiative in regulatory measures ${ }^{\underline{8}}$. This passive

\footnotetext{
${ }^{7}$ In Europe and the US, voluntary codes of conduct in nanotechnologies are being created by nongovernmental organizations. The German company TÜV SÜD's riskmanagement certification system called CENARIO ${ }^{\circledR}$, the Swiss Retailer Association (IG DHS) in Europe, and Dupont and the Environmental Defense Fund in the United States are good examples of this.
}

attitude is further fostered by the role played by most Japanese industrial associations as interfaces between government and industry. Industry associations are major routes for the dissemination of new governmental policies and, at the same time, for the collection at a national level of the voices of individual firms to transmit them to the government $\stackrel{9}{\text {. How- }}$ ever, in the food industry, many associations are involved in manufacturing, wholesaling, and retailing, with at least 3 associations operating within the retailing sector in Japan. This fragmented nature of industrial associations in the food industry makes it difficult to create a single voice with which to urge the government to take regulatory action on food nanotech.

The case of food nanotech is heading in a rather different direction, namely avoidance of a highly regulated market and avoidance of being identified as 'nano.' While the term 'food nanotech product' covers a wide range of products, dietary supplements are the most popular product area in which food nanotech is applied. This is observable if we take a look at product inventories created in Japan and the US. Dietary supplements are an area in which the regulatory hurdle is not high, as the sale of supplements does not require pre-market permission from regulatory bodies nor mandatory labeling of materials. For such products, it is left up to a company's discretion as to what information is disclosed. In fact, some companies avoid using the term 'nano' for their products even at their development stage. This tendency is salient, in particular, for the European food industry, where some environmental groups oppose the use of nanotechnology in food and agriculture. Companies there prefer to use alternate phrases, such as 'bottom-

\footnotetext{
${ }^{8}$ These answers were responses to open-ended question regarding regulatory issues related to food nanotech. Regulatory measures were requested for items, in particular those that show novelty compared with traditional counterparts. The respondents were opposed to regulations and labeling items with respect to traditional use or eating experiences (Toray Research Center 2010). ${ }^{9}$ One of the major industrial associations of the food industry is the Japan Food Industry Center (Shokuhin Sangyo Center), which is a federation of associations within the food processing industry. The center has a retired official of the MAFF as chairperson. Its members are mainly food manufacturers, as food retailers and restaurant chains belong to other industrial organizations. In Japan, it is typical for industrial organizations to have former government bureaucrats as high-ranking officials in order to foster ties with related ministries. This organizational custom may foster a passive attitude of waiting for government directions rather than an organization itself taking the initiative.
} 
up' and 'self-assembly.' This avoidance of the term 'nano' can be regarded as one of the reactions by companies to regulatory uncertainty.

\section{Consumers}

Basically, consumers in Japan tend to have quite a positive image of nanotechnology. This tendency was demonstrated in a multi-year survey conducted by Kishimoto et al. (2010). However, it is difficult to know what kind of image they have of food nanotech. Based on experiences gained in participatory technology assessments, we find that consumers hold both positive and negative expectations with respect to food nanotech (Mikami et al. 2009). Consumers have expressed their wishes to food nanotech researchers to develop food that would be helpful to people with digestive problems, and for food-processing technology that helps save resource. At the same time, consumers want adequate information provided through mandatory labeling, and they want to maintain their right to choose. Participants in the event understood that food nanotech is an emerging technology, and, therefore, still involves uncertainties that need to be explored. This is why participants in the event regarded the provision of information as crucial and emphasized the importance of labeling and the right to choose.

While an appreciation of this feeling of uncertainty is important to understanding consumers' responses to food nanotech, there are some occasions where consumers have neither an interest nor a stake in food nanotech. This situation happens when nanotechnology is only applied in phases that have no impact on the nature of the final products. If food nanotech applications were limited to the processing stage and had no effects on final products (B2B technology), consumers would pay little attention to food nanotech. In this case, uncertainty over food nanotech would fall outside the purview of consumer interests. On the contrary, if specific applications were to impact human health and the environment, consumers would raise their voices to demand the introduction of appropriate regulations. Currently, it is impossible to anticipate the way in which food nanotech will be applied to different products. There will be differentiated interests and risks to consumers depending on the applications. This is why consumers and civil society organizations have a vested interest in exercising their influence over regulatory bodies and respond to regulatory uncertainty in an appropriate direction from their points of view.

\section{RECONSTRUCTING UNCERTAINTIES AND STAKES BY STAKEHOLDERS}

In this section, I summarize the observations made above and draw some implications based on the 3 types of interaction between uncertainty and stakes as explained below. Stakes mean here the interests or concerns that specific groups of people hold, or society as a whole holds in the broadest sense. Sometimes the stakes are not self-evident to the stakeholders, and I would like to discuss how the stakes could be reconstructed by negotiations among stakeholders. The same is true for uncertainty. Uncertainty does not exist just 'out there,' but could be reconstructed in a more manageable form for stakeholders.

Put shortly, I would like to discuss how stakes and uncertainty are negotiated and reconstructed through interactions among stakeholders. I argue that there can be 3 types of responses regarding uncertainty and stakes, which are (1) trying to reconstruct uncertainty while the stakes are regarded as given, (2) trying to reconstruct stakes while the uncertainty is regarded as given, and (3) trying to reconstruct uncertainty and stake at the same time. I will explain these 3 types in detail in the following section.

\section{Reconstructing uncertainty when stakes are regarded as given}

First, I would like to describe a situation in which stakeholders reconstruct uncertainty based on their given roles. In this case, the stakes are untouched or nonnegotiable. Various kinds of stakeholders, such as companies and researchers, might take this kind of action. For example, researchers are often asked to engage in research activities to find answers to risk issues. Researchers, in particular those outside private companies, are expected to play an important role in investigating scientific uncertainty and collect useful data related to risk issues. Typically, under publicly funded research, it is the mission of researchers to accumulate data that are useful in assessing risk. Controlling or reconstructing uncertainty into an amenable one is their strategy. In addition, some private companies are taking the initiative in collecting risk data and publicizing them to maintain the integrity and accountability of their products. We have identified some companies that are implementing this kind of strategy.

Some companies may emphasize their long history of safe food nanotech use by referring to cyclodextrin 
and nanoparticles in traditional food. This is a way of giving the impression to consumers that food nanotech is not a novel technique, but a continuation of existing technology. By referring to continuity, uncertainty is regarded as manageable as far as certain food nanotech products are concerned.

Consumers or consumer organizations who try to control uncertainty by adopting a more radical method are included here. The consumer stake is nonnegotiable when consumers think they are facing risks in their daily lives. Uncertainty can be regarded as a risk, and precautionary measures are preferred to be taken when considerable risks are regarded as unavoidable. Therefore, consumers take measures to control and reduce uncertainty, including opposition to the commercialization of food nanotech product or requesting labeling on such products so as to avoid uncertainty.

\section{Reconstructing stakes when uncertainty is regarded as given}

Contrary to the above-mentioned situation, the situation here pertains when stakeholders try to control their stakes when the uncertainty is regarded as given. Reconstructing stakes can be achieved by increasing/decreasing their responsibilities, concerns, and interests related to food nanotech. While leaving uncertainty untouched, stakeholders can take a larger or smaller responsibility based upon their strategy.

Some companies are disclosing their research data in the hopes that this activity shows their responsibility toward consumer products. As uncertainty cannot be resolved within a short period of time, these companies take their responsibility seriously and show their responsiveness to uncertainty to consumers.

The opposite can happen when stakeholders try to avoid being identified as such. This is related to the problem of stakeholder identification. The lack of a definition, in particular a 'regulatory' definition, of food nanotech creates significant uncertainty with respect to the scoping of regulated articles, and therefore, directly affects who can be classified as stakeholders in the food industry. In this situation, we observe that some companies are trying to avoid being identified as stakeholders by avoiding the use of the term 'nano.' This is done by taking advantage of uncertainty. In other words, without a relevant definition of food nanotech, industry might eschew being identified as stakeholders in food nanotech. As I mentioned above, this situation is, in particular, true in Europe where the food industry avoids using the term 'nano.'

This avoidance of being identified as a stakeholder can occur unintentionally. I would like to quote my own experience of interviewing an association. When I visited an industry association related to health food with colleagues in early 2009, the president of the association said he knew of no food nanotech products in the Japanese market at that time that could be categorized as a health food. The reality was not true. At the time of our visit to the association, there were health food products being sold on the market that claimed to be using nanotech. This tells us that it is difficult to have effective communication with stakeholder(s) when there is no agreedupon definition. The president had not recognized any health food products on the Japanese market; therefore, he did not regard himself as a stakeholder in food nanotech. Given the current regulatory uncertainty, industry associations are not well prepared to be stakeholders as such.

\section{Reconstructing uncertainty and stakes simultaneously}

The last type is an attempt to control both uncertainty and stakes simultaneously. This endeavor can be achievable only by actors that can both influence the allocation of stakes and control industrial development. Stakeholders that have this kind of influence are, I argue, regulatory agencies and industry associations. Regulatory agencies can delineate uncertainty and stakes at the same time by setting a regulatory framework for food nanotech taking into account scientific information, and allocate stakes/ responsibility among various actors. Regulatory agencies can do this using either a hard law or a soft law approach.

As for the soft law approach, industry associations could initiate this approach and make a similar attempt to control both uncertainty and stake. For example, industry associations could introduce a voluntary code of conduct on specific types of products in order to reduce uncertainties, such as product safety testing before placing products on the market. As scientific knowledge and regulatory experience are accumulated, this type of approach would change over time in an adaptive way to accommodate uncertainty, and likewise stakeholders would also be changed over time as the area of application of food nanotech would change. 
Reconstructing both uncertainty and stake would not always mean both of them would be changed in the same direction. Sometimes, a regulatory agency might try to arrange a situation in which there is a trade-off between the two. For example, a regulatory agency could impose a heavier onus on industry to demonstrate safety if it attempts to put a product on the market based on the precautionary principle. In this case, a regulatory agency would be trying to reduce uncertainty by increasing the stakes of manufacturing companies.

However, with respect to the current situation in Japan, neither regulatory agencies nor industry associations have attempted to take this route. As I have described above, this regulatory inaction by the Japanese government shows a sharp contrast with that of EU and US governments. Industry associations also have not initiated action to create voluntary codes of conduct, such as those stipulated in the United States.

\section{CONCLUSION}

In this paper, using a case study of food nanotech in Japan, I discussed how emerging technology entails different kinds of uncertainties and how various stakeholders respond to these uncertainties. I have elucidated 3 ways to respond to these situations by focusing on stakes and uncertainties. As I have mentioned above, stakes and uncertainties do not exist untouched, but rather they are reconstructed through negotiations or the strategic behavior of stakeholders.

We can draw some ethical implications from the reactions of stakeholders. We have observed differences in terms of stakeholder responses toward uncertainty. For example, while some companies are actively disclosing information on their food nanotech products, others try to avoid being identified as stakeholders. The difference in attitudes might be based on the policies of the companies, as there are no regulatory provisions so far related to this kind of information provision. Asymmetry in information exchange between industry and consumers is typically very pronounced in the case of an emerging technology and, therefore, this kind of issue is raised if societal stakes related to the technology are regarded as high. During one of the participatory events that my colleagues organized, the introduction of a third-party certification system was seen as an appropriate measure to resolve this issue as no governmental intervention is expected in the near future in Japan. This is a situation where consumers or consumer organizations can play a role in asking the government or industrial associations to introduce this kind of scheme into the marketplace, or to start discussion as to the way in which information provision could be organized within society. Who should be involved in deciding the manner in which information is accumulated and/or distributed is an important issue and should be decided by an ethical judgment made by society as a whole.

As I have described in the previous section, there are 3 ways to respond to uncertainty and stakes by stakeholders; all of the responses will cause further reactions by other stakeholders as time goes by, and it is very important to accommodate these changes in the future. In this sense, so-called adaptive management (Steelman et al. 2005) is regarded as an appropriate scheme for the risk management of emerging technologies. As new scientific information is found and industrial applications expand, it is desirable for all actors involved to respond to such new situations in a flexible way. However, as the lessons from genetically modified organisms (GMOs) suggest, precautionary measures for labeling GMOs resulted in an industry backlash by not labeling products as such, which ultimately penalized this emerging technology. The possibility of adaptive management has become very small because of a pre-decision made by interested stakeholders such as supermarkets. In this sense, risk-management measures can sometimes have effects that are irreversible; therefore, these measures may have a pass-dependent character. Based on this argument, even the regulatory inaction of the Japanese government might have already caused an irreversible effect that might have a different effect compared with that in the EU and US $\underline{\mathbf{1 0}}$.

Overall, uncertainties surrounding emerging technologies present various governance issues to regulators, the market, and the public in general. This paper has touched upon only some issues, such as the reactions of stakeholders and the ways in which stakeholders try to reconstruct their stakes or uncertainties. In order to understand the dynamic nature of responses and negotiations among various stakeholders, work needs to be done taking into

\footnotetext{
10 Some of the results of this regulatory inaction are shown by the fact that various products are already on the market, and a highly positive image of the word 'nano' is prevalent among the Japanese (Kishimoto et al. 2010). Once regulatory action is taken, this high level of positive perception could be greatly affected, and this is a situation about which industry has strong concerns.
} 
account other important factors, such as international regulatory trends and nanotech regulation in other fields of applications. These agendas are left as future work.

Acknowledgements. I express my appreciation for the financial support provided by the Japanese Society for Promotion of Science (JSPS) funding (funding nos. 21380135 and 22228003), and the I2TA project funded by the Japanese Science and Technology Agency, Research Institute of Science and Technology for Society (JST/RISTEX).

\section{LITERATURE CITED}

EFSA (European Food Safety Authority) Scientific Committee (2011) Scientific opinion: guidance on the risk assessment of the application of nanoscience and nanotechnologies in the food and feed chain. EFSA J 9:2140

ETC Group (2004) Down on the farm-the impact of nano-scale technologies on food and agriculture. ETC Group, Ottawa. Available at www.etcgroup.org/en/ node/80

FDA (Food and Drug Administration) (2007) Nanotechnology: a report of the US Food and Drug Administration Nanotechnology Task Force. FDA, Rockville, MD. Available at www.fda.gov/downloads/ScienceResearch/SpecialTopics/Nanotechnology/ucm110856.pdf

FDA (2011) Considering whether an FDA-regulated product involves the application of nanotechnology. Guidance for industry (Draft guidance). Available at www.fda.gov/ RegulatoryInformation/Guidance/ucm257698.htm

Friends of the Earth (2008) Out of the laboratory and onto our plates: nanotechnology in food and agriculture. FoE Australia, Europe, USA. Available at http://nano.foe. org.au/node/220

Funtowicz SO, Ravetz JR (1993) Science for the post-normal age. Futures 25:739-755

Gergely A, Bowman D, Chaudhry Q (2010) Small ingredients in a big picture: regulatory perspectives on nano-

Editorial responsibility: Tomiko Yamaguchi, Tokyo, Japan Karen Cronin, Wellington, New Zealand, and

Daryl Macer, Bangkok, Thailand technologies in foods and food contact materials. In: Chaudhry Q, Castle L, Watkins R (eds) Nanotechnologies in food. RSC Publishing, Cambridge, p 150-181

Jasanoff S (ed) (2004) States of knowledge: the co-production of science and social order. Routledge, London

Kishimoto A, Takai T, Wakamatsu H (2010) Nanotechnology ni taisuru Ninchi Taido Koudou ni tsuiteno Teiten Kansoku: 2005-2009 (Fixed point observation of perception, attitude, and behavior regarding nanotechnology). AIST, Tsukuba. Available at: http://staff.aist.go.jp/kishimotoatsuo/nano/nano_20052009.pdf (accessed November 20, 2011) (in Japanese)

METI (Ministry of Economy, Trade and Industry) (2005) Survey on market trend of nano-related products. Investigated by Fuji Keizai. METI, Tokyo (in Japanese)

Mikami N, Sugiyama S, Takahashi Y, Yamaguchi T, Tachikawa M (2009) Jouryu deno sanka ni consensasu kaigi wa tsukaeruka (Is a consensus conference suitable for 'upstream engagement'?). Jpn J Sci Commun 6:34-49 (in Japanese)

Murakami Y (1984) Sin-Chukan Taisyu no Jidai (Age of new middle class). Chuo-Koron-sya, Tokyo (in Japanese)

Pelley J, Saner M (2009) International approaches to the regulatory governance of nanotechnology. Regulatory Governance Initiative, Carleton University, Ottawa

Steelman TA, Coe-Juell L, Cromley CM, Edwards CM, Tucker DW (2005) Adaptive governance: integrating science, policy, and decision making. Columbia University Press, New York, NY

Toray Research Center (2010) Report on safety assessment information regarding food nanotechnologies. Food Safety Commission, Tokyo

USDA (United States Department of Agriculture) (2003) Nanoscale science and engineering for agriculture and food system. State Research, Education and Extension Service, USDA, Washington, DC

Yamaguchi T (2010) Discussing nascent technologies: citizens confront nanotechnology in food. East Asian Sci Tech Soc: Int J 4:483-501

Yamaguchi T, Hibino A (2009) Houga suru Kagaku-Gijutu (Emerging science and technology). Kyoto University Academic Press, Kyoto

Submitted: August 31, 2011; Accepted: January 30, 2012

Proofs received from author(s): April 25, 2012 